\title{
The Expansion of Cash Cropping; Implications on Gender Division of Roles: A Case Study from Gedeo Community - Southern Nation Nationalities and Peoples Region, Ethiopia
}

\author{
Takele Bekele Bayu \\ Department of Pedagogy and Morality, College of Social Science and Humanities, Dire Dawa University, Dire Dawa, Ethiopia
}

Email address:

takebek1983@yahoo.com

\author{
To cite this article: \\ Takele Bekele Bayu. The Expansion of Cash Cropping; Implications on Gender Division of Roles: A Case Study from Gedeo Community - \\ Southern Nation Nationalities and Peoples Region, Ethiopia. International Journal of Sustainable Development Research. \\ Vol. 3, No. 2, 2017, pp. 7-17. doi: 10.11648/j.ijsdr.20170302.11
}

Received: January 30, 2017; Accepted: February 27, 2017; Published: May 27, 2017

\begin{abstract}
The overall objective of this paper was to investigate trends, status of cash cropping and its implication on gender division of roles in agricultural production. It has also further aimed to examine trends of decision making power on household resources. It has made use of primary and secondary data sources and 117 households were selected through systematic random sampling. Mix of qualitative (context analysis and narration) and quantitative (simple descriptive statistical tools) data analysis method was employed. The study was conducted on the basis of a premise that there are changes in gender division of roles due to the expansion of cash cropping patterns in the study area. The study discloses that traditionally, coffee production belongs to men since it generates the necessary income while being sold in the local market but women have no role at all. However, with the expansion of the market for coffee production men began to look at woman's labor and in effect the involvement of women seems to have increased in the sector. The finding of this particular study further implies that despite their labor share in the sector, women have limited access to and control over the dominant cash crop in the community, coffee production, which in turn limited their access to capital. Therefore, the concerned stakeholder should work hard and exert coordinated efforts to harness gender disparity in the cash cropping sector to the end achieve gender equality and equity in the agricultural sector.
\end{abstract}

Keywords: Expansion, Cash Cropping, Gender Roles, Tradition

\section{Introduction}

Women supply a large proportion of the agricultural labor and in some societies produce up to 80 percent of the food crops (FAO 2007b). Failure to recognize this contribution is costly. It results in misguided policies and programs, forgone agricultural output and associated income flows, higher levels of poverty, and food and nutritional insecurity (World Bank 2007).

While women provide the majority of the labor in agricultural production, their access and control over productive resources is greatly constrained due to inequalities constructed by patriarchal norms (Doss, 1999). According to Fernando (1998), activities, resources and opportunities of people are significantly influenced by gender- that is, by the socio-economic and cultural dimension of being male or female. Moreover, different types of activities and tasks are generally allocated to women and men within the family in terms of subsistence production and production for the market.

In Sub-Saharan Africa, men dominate cash crop production or other income generating activities, relegating the production of food on women (Boserup, 1970; Doss, 2002). Guyer and White (1984), note that the introduction of cash crop production attracted men into commercial agriculture and with the increased investment of men in such productive sphere; women were relegated to domestic chores. Generally, crops produced for household consumption and micro scale crop production for local market (eg. Vegetables, fruits and tubers in Sub-Saharan Africa) are cultivated and marketed by women. More commercial or industrialized crops cultivated on a much larger scale for direct export or for further processing, such as cotton or sugar, are more frequently the economic domain of men (Koehler, 1999). 
However, in the livestock sector, women share responsibility with men and children for the care of animals, and particular species and types of activity are more associated with women than men. For example, women often have a prominent role in managing poultry (FAO 1998; Guèye 2000; Tung 2005) and dairy animals (Okali and Mims 1998; Tangka, Jabbar and Shapiro, 2000) and in caring for other animals that are housed and fed within the homestead.

Generally, Partly the social norms - men responsible for meeting cash needs and women responsible for meeting food needs of the household, and partly the policy mis-function introduction of new crops, improved varieties, agricultural training and extension target mainly men, explain under representation of women in cash crop production (Diksha, 2014). However, Doss (2002) has strongly argued that gendered patterns of cropping may change over time.

In Ethiopia, women are commonly responsible, along with their children, for taking care of small livestock, production and marketing of butter, cheese, and vegetables (JICA 1999). Ethiopian women and girls bear the greatest burdens of food insecurity, since they play a significant role in livestock maintenance, crop production and marketing of rural produce (Ethiopian Ministry of Foreign Affairs, 2010). In the study area, women are responsible for herding, tending to sick animals, watering, barn cleaning, milking and milk processing ((District Agricultural and Rural Development Office, 2015). According to district office of agriculture, it is women who take most responsibility for the household food production, and income generation. Despite this, women's access to productive resources; their access to and adoption of modern agricultural inputs and technologies; and their access to credit and extension services are severely constrained in much of the developing world (FAO, 2011). Moreover, the traditional role of women puts gender specific constraints on access to resources such as fuel wood, water resources, post-harvest activities, and livestock management (Dejene 2003; Teshome and Devereux 2005).

It is well documented that crop marketing and the control over revenues from these sales, is often gender differentiated, and in some cases vary by crop type. Many female farmers bring the vegetables and fruits, the production of which they manage, to the market, and may retain these incomes to pay for household needs. In contrast, the marketing and income from cash crops grown by the household in larger scale, such as coffee, teff, and chat, are controlled by the household head (who is nearly always male in households where the head has a spouse in the household), though there are many cases where small quantities of these important crops may be sold by the head's spouse.

It is therefore, the purpose of this particular study to investigate the expansion of cash crop production and its implication on gender division of roles in the agricultural sector.

The overall objective of this paper therefore is to investigate trends, status of cash cropping and its implication on gender division of roles in agricultural production amongst the Gedeo farming community.
Specifically, it:

- investigates the dynamic nature of gender division of roles in the agricultural sector;

- examine the impact of patterns of cash cropping on gender division of roles in the agricultural sector;

- Investigate changes and continuity in gender division of roles in the agricultural sector;

\section{Literature Review}

Global and national evidence clearly shows that rural women play critical roles in bringing about food and economic security for their households (FAO 2011b; CSA and ICF International 2012, 246-260; Gobezie 2010, 27; Jones, Tafere, and Woldehanna 2010). Due to this mounting evidence, greater attention is being paid to ensure that agricultural policies and programs are gender sensitive and address barriers to women's equal participation and benefit in rural producer groups and cooperatives (FAO 2011b, 2012; World Bank 2009, 63-70; USAID 2012).

African agricultural systems have historically been described as female centered due to the predominance of shifting cultivation (Boserup 1970). More recent studies which have dealt with gender and farming are primarily concerned with the importance of recognizing the vital but often invisible role of women in African agriculture. Findings by $(\mathrm{FAO}, 2008)$ on women in Agriculture showed that women make up over half of the agriculture labor force yet they were frequently subjected to discrimination, poverty and hunger.

Particularly, as economies become more technologically developed, women are increasingly withdrawn from production or forced into the subsistence sector. In this regard, Boserup (1970) has recognized that rural women play a crucial role in determining and guaranteeing food security and well-being for the entire household while men take center stage in the production of cash crops. Though women make essential contributions to agricultural development, they face specific constraints that disadvantage them in relation to men_(ALINe; 2011). Facilitating women's access to agricultural inputs, resources and services so as to increase agricultural productivity and ensure food security is a frequently raised theme in the literature.

Due to this mounting evidence, greater attention is being paid to ensure that agricultural policies and programs are gender sensitive and address barriers to women's equal participation and benefit in rural producer groups and cooperatives (FAO 2011b, 2012; World Bank 2009, 63-70; USAID 2012). In this respect, several studies have tried to look into gender in relation to food security (Kebede 2009; Ibnouf 2009; Gawaya 2008; Scanlan 2004), the adoption of agricultural technology (Doss 2001; Doss and Morris 2001), gendered patterns of cropping (Carr 2008; Doss 2002), agricultural productivity (Croppenstedt et al. 2013; Tiruneh et al. 2001) and land rights (Gebru 2011; Holden et al. 2011; Kevane and Gray 2010; 1999; Yngstrom 2002). 
Ethiopian women's status is low where they: (a) are generally poorer than men because they earn less; (b) are less educated; (c) are increasingly becoming heads of households, with no resources to support their dependents; (d) do not enjoy due acknowledgment for their labour contribution, particularly in agriculture, and (e) do not have decision making power (Sida, 2003). Ethiopia is a patriarchal society that keeps women at a subordinate position, using religion and culture as an excuse (Ibid).

Gender division of labour in rural Ethiopia varies in terms of farming systems, cultural settings, location and the different wealth categories (Abera et al. 2006; Mollel and Mtenga 2000). Research in Ethiopia shows active participation of women in the agricultural production. However, their access to improved farming system, skill training and extension services as well as information on marketing strategies and research out-puts is limited (Mulunesh, 2001). The traditional patriarchal system of resource control limits women's access to and control over productive resources (Bogalech, 2001). Among the people of konso, despite their pivotal role in food production, women have no decision making power over important resources like land, livestock and house (Yilima, 2002). Sintayehu (2000) has found that despite change in agricultural technologies and institutional arrangements there is no change in gender division of roles among the Sidama community. Almost all studies focuses on women's contribution in the agricultural sector, access and control over productive assets as well as the implication of change in technology and institutional arrangement on gender division of roles in the sectors. The expansion of cash crop production and its implication on gender division of roles is not well investigated.

This study, therefore, investigates gender division of roles in the traditional Gedeo community of Southern Ethiopia and critically analyzes the implication of the expansion of cash crop production on gender division of roles in the study area.

\section{Material and Methodology}

\subsection{Location, Population and Biophysical Conditions}

The study Woreda (district) is located in Gedeo zone of Southern Nations, Nationalities and peoples' Regional State (SNNP), Ethiopia. Wonago Woreda is one of the six Woredas' of Gedeo zone and located at about 374 kilometers South of Addis Ababa and 100 kilometers South of Hawassa, capital of Southern Nations, Nationalities and Peoples' State and 14 kilometers South of Dilla, which is the capital of Gedeo zone (Figure 1). Wonago Woreda has a total population of 117,630 (male 58,522, female 59,108), (CSA, 2008).

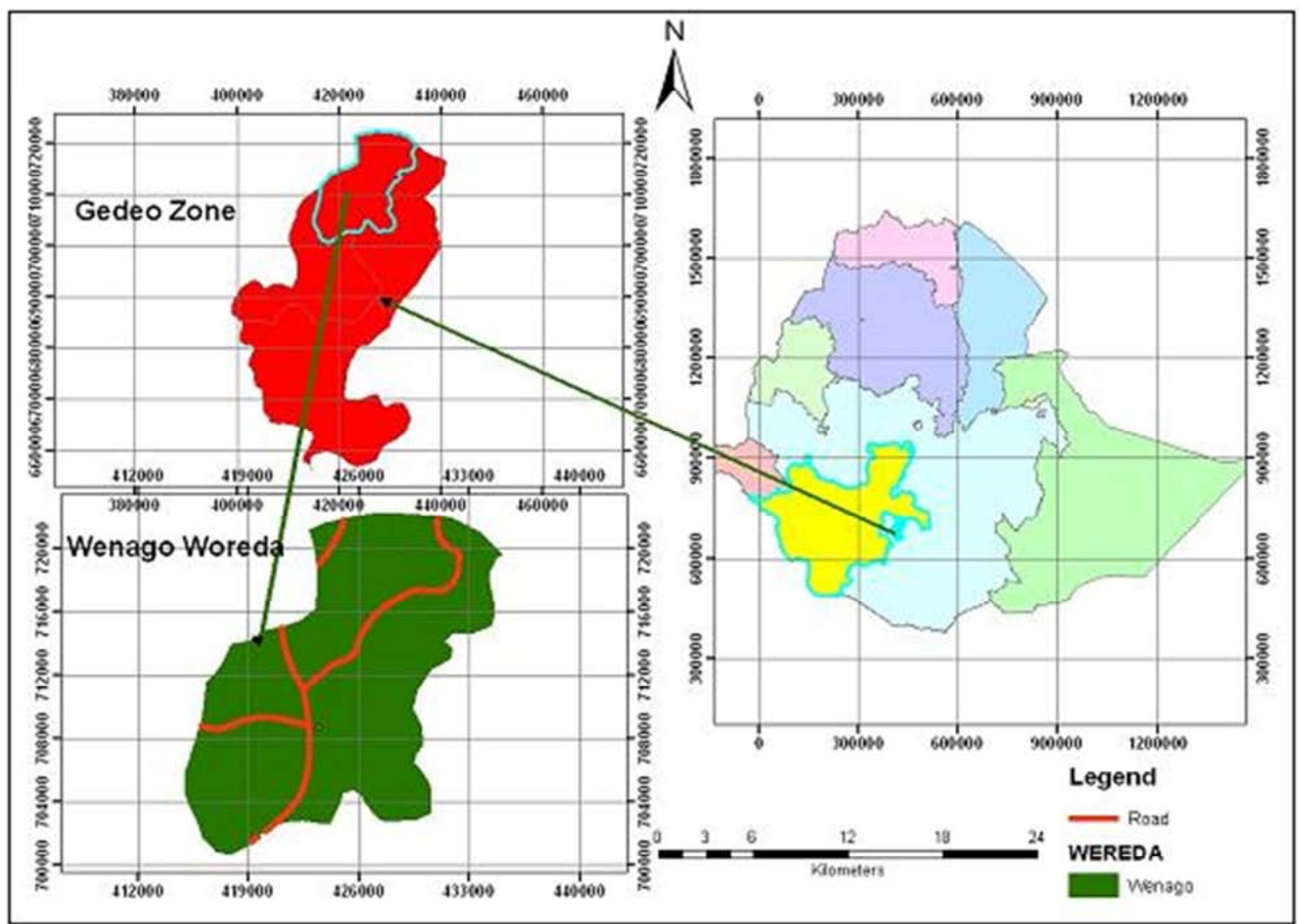

Sources: Ethio-GIS, 2015

Figure 1. Study Area Map. 
Wonago Woreda is organized administratively in to 17 kebele adminstrations (the lowest administrative unit). Among those kebele administrations, Tumata-Chirecha and Sugalle were selected as the research site, purposefully. The sites were selected due to researcher's familiarity to the area and Wonago Woreda, among the Zonal Woredas', is known in its cash crop production.

- Tumata-Chirecha kebele administration has a total population of 6919. Climatically, Tumata-Chirecha is characterized by Woinadega (cool and sub moist) and dominantly by Kola (hot, dry and low land). The kebele farmers practice plough farming system since 1987 . The dominant crops that are grown in the kebele include: coffee, fruits and vegetables, sweat potato, maize, sorghum, teff, and sugarcane.

- Sugalle, the second sample kebele has a total population of 7122. Sugalle has a mountainous and rugged topography and has a Woinadega and Dega (cold, humid and high land) agro-ecological zones. Farmers in the kebele practice hoe-based farming system. Crops grown in the kebele are coffee, fruits and vegetables, sweat potato, sugarcane and maize.

Wonago Woreda has different climatic condition. Among the climatic zones of the Woreda, the following are dominant: Woinadega, Dega and Kolla which constitutes $54.5 \%, 39.5 \%$ and $6 \%$ respectively. The Woreda has an average annual temperature of $29.23 \mathrm{c}$ (highest) and $11.23 \mathrm{c}$ (lowest) and with an annual rainfall of $1449 \mathrm{~mm}$ (highest) and $873 \mathrm{~mm}$ (lowest). The Woreda is found at an elevation of 1570-2070 above sea level (WWARDO, 2015). With regard to vegetation cover, Wonago Woreda has vegetation cover that ranges from small bushes and acacia trees to very long endemic trees.

\subsection{Economic Condition of the Study Area}

The Gedeo community is dominantly an agrarian society and agriculture is the main-stay of the community. It belongs to the enset-complex farming system. It represents a mixed type of sedentary agriculture with intensive utilization of land resulting from high population pressure. The Gedeo highland communities are engaged in production of enset (false banana), coffee, fruits and vegetables and livestock. Cash income of the community is generated mainly from the production of cash crops particularly coffee. The Gedeo communities are known for their coffee known by the name of Yirgachefe coffee. The second important source of cash income of the community is production of fruits and vegetables (Avokado, Mango, Papaya, Banana, and Cabbage). Enset is the staple food of the community. The production of enset is carried out by women. The land use pattern in the Woreda at the time of data collection (Feb. 2015) reveals that 679.95 hectare is covered by annual crops, 11559.5 hectare is covered by perennial crops, 203.94 hectare is (fragment) forest, 530.36 hectare is covered under construction, 543.96 hectare is grazing land and 81.5 hectare is others (WWARDO, 2015). Due to land degradation, land fragmentation and prevalence of soil erosion, the community is expanding agro-forestry system.

\subsection{Methodology}

\subsubsection{Data Sources and Instruments of Data Collection}

Data were collected on cash cropping patterns and its implication on gender division of roles. Data collected using structure questionnaire, deep interview, key informant interview, focus group discussion and observation method. The quantitative survey data was supplemented by qualitative data collected from different respondents in the study area.

\subsubsection{Sample and Sampling Techniques}

A four-stage sampling strategy was used to select farm households for the study. After selecting the study woreda, two kebeles were selected purposefully, dominant in cash crops production. In selecting the kebeles, all kebeles of the woreda were first stratified in to cash crops and food crops areas. Both kebeles are dominantly inhabited by Gedeo community. Finally, farm households were selected randomly employing systematic sampling procedures. Since both kebeles have almost equal farm household population, 60 farmers were selected from each of the selected kebeles, making the total sample size 120. A total of 117 sample households were used for analysis since the three sample households' movie incomplete data.

\subsubsection{Methods of Data Analysis}

Combinations of both qualitative and quantitative methods were employed to analysis the data. Quantitative were edited, coded and entered in a computer and the Statistical Package for Social Science (SPSS) software version 11.5 spread sheet was used for the analysis. Descriptive statistics were run to give frequencies and then cross-tabulation was undertaken. Multiple response questions were analyzed so as to give frequencies and percentages. Moreover, Qualitative data from various sources were analyzed contextually and presented in the form of narration.

\section{Result and Discussion}

\subsection{Gender Division of Roles in the Agricultural Sector Among the Gedeo Farming Community}

The gender division of roles in agricultural production by tasks is common in the study area. The data gathered from both hoe and plough culture indicates that there are tasks that are assigned to husbands and there are also tasks given to wife. However, now a day these demarcations of tasks are not absolute. Women and men among the Gedeo community participate in different agricultural tasks in various degrees.

\subsubsection{Gender Division of Roles in Crop Production}

In the traditional Gedeo community women had limited role in agricultural production. As to the FGDs, the role of women in agricultural production was limited to the preparation of enset for household consumption and 
marketing purpose. In addition to these, Women in the community were responsible for household tasks. Almost all farming tasks in crop production were done by men. Farming tasks like land clearing and preparation, hoeing, planting, weeding, harvesting, storing were considered as the responsibilities of men farmers in the community. These tasks were culturally considered as men's activities in the community. However, women can participate in marketing activities.

Case-1 women's role in agricultural production was low among the traditional Gedeo communities

IN1, 39 years of old. For the question that what is your traditional agricultural tasks? She responded that:-

"In the traditional setting it was our duty to provide husbands' with food and coffee while they work on agricultural field's and returns back for our domestic chores. Almost all agricultural activities were carried out by our husbands. Apart from these, our role in agricultural production was limited to marketing cabbage, and enset products." Although in a limited extent, we also involve in marketing fruits and vegetables production."

The above finding indicates that men assume almost all agricultural tasks while women's role limited to the preparation and the provision of meals. Though women do not play major role in the field tasks, their limited involvement in the marketing of fruits and vegetables is remarkable.

However, in recent years the involvement of women in agricultural production has been increased. The reason for this, as revealed in FGDs and in-depth case interview, is the changes in the socio-cultural, economic and political life settings of the community. The socio-cultural attitudes had not allowed women for instance to inherit and control agricultural resources like land, livestock and categorized agricultural tasks like land clearing and preparation, hoeing, planting, harvesting and storing under men's tasks. However, the awareness created by different stakeholders like NGOs working on gender and agriculture in the Woreda, Woreda women affair office, Woreda agricultural and rural development office and extension workers contributed a lot in changing those socio-cultural attitudes. Traditionally, the production and marketing of cash crops particularly coffee considered as men's task. However, the integration of Gedeo community in to local and international market through coffee production (as economic element) changed the gender aspects of tasks in agricultural production. In the customary land holding system, women had only access to land through their husband. Control over land belongs to the husband. However, policy reforms like the formal land certification processes, as a political element, enabled woman to have access to and control over land. As a result of changes in the aforementioned factors, women's involvement in agricultural production has been increased and currently use family labor is common in the study area as indicated in the survey result which is depicted in the table below (1,2,3 and 4)

Therefore, in the contemporary Gedeo farming community women share certain responsibility with their men in agricultural production. The gender division of roles in agricultural production in this way seems to take another direction (Table 1).

Table 1. Gender division of roles in crop production.

\begin{tabular}{|c|c|c|c|c|}
\hline \multirow{3}{*}{ Farming Tasks } & \multicolumn{4}{|l|}{$(\mathrm{N}=117)$} \\
\hline & \multicolumn{4}{|c|}{ Responsible person } \\
\hline & Husband & Wife & Both, mainly husband & Both, mainly wife \\
\hline Land clearing \& preparation & $108(92.3)$ & - & $9(7.7)$ & - \\
\hline Ploughing & $117(100.0)$ & - & - & - \\
\hline Hoeing & & - & $117(100.0)$ & - \\
\hline Planting & $81(69.2)$ & - & $36(30.8)$ & - \\
\hline Weeding & $21(18)$ & - & $96(82)$ & - \\
\hline Harvesting & - & $10(8.6)$ & 107(91.4) & - \\
\hline Transporting the harvest & $5(4.27)$ & $1(0.85)$ & $95(81.19)$ & $16(13.6)$ \\
\hline storing & $16(13.7)$ & - & $101(86.3)$ & - \\
\hline Marketing & $15(12.8)$ & - & $97(83)$ & $5(4.2)$ \\
\hline
\end{tabular}

Source Own Survey, Feb. 2015 * Figures in parenthesis are percentages

As the table reveals, in the contemporary Gedeo community both men and women take share of responsibilities in agricultural production, though husband still has the biggest share in the sector. Ploughing is still the activity of men but in hoeing women have some role as indicated in the above table. Further, women participates in land clearing and preparation planting, weeding, harvesting, transporting the harvest, storing and marketing activities unlike their role under the traditional settings. The interview conducted with respondents has also supported the idea that recently women began to take part in major agricultural tasks.

Case-2 women's role in agricultural production was low among the traditional Gedeo communities

IN2, 41 years of old. For the question, unlike in the traditional setting, what changes in the gender division of roles, if any you observed, due to various changes (socioeconomic and political) in the community and the nation in general? She responded that:-

"In traditional setting, we, women had the role of meal preparation and provision as well as a limited participation in selling of fruits and vegetables just for the purpose of household food security. But recently due changes in the socio-cultural, political and economic arena, we began to take minor role in major agricultural tasks in support of our husbands." 


\subsubsection{Gender Division of Roles in Livestock Production}

Women in the traditional Gedeo community play a vital role in the operation and management of livestock production unlike their role in arable farming. The FGDs revealed that women unlike their men counter parts take the biggest share in livestock production. Women in earlier days take full charge of tasks like barn cleaning, milking and milk processing, marketing milk and its products and poultry production. The following case explains this point:-

Case-3 in the traditional Gedeo community women take active role in the operation and management of livestock production.

IN3, is 46 years of old. She explained women's traditional role in livestock production in a way that:-
"Unlike our men counter parts; we had been taking the day -to - day activities in the livestock

production. We were responsible in barn cleaning, milking, marketing milk and its products. Indeed,

herding, supplying fodder and taking animals to the health center were mainly conducted by men.

However, now a day we also participate in every aspects of livestock production."

The above idea is true irrespective of farming system. This is because the same idea was reflected among women farmers from plough culture.

The gender division of roles in livestock production among the Gedeo farming community is shown in Table 2. As the Table reveals, women take the largest task share in the sector.

Table 2. Gender division of roles in livestock production.

\begin{tabular}{|c|c|c|c|c|c|}
\hline \multirow{3}{*}{$\begin{array}{l}\text { Tasks in livestock } \\
\text { production }\end{array}$} & \multicolumn{5}{|l|}{$(\mathrm{N}=117)$} \\
\hline & \multicolumn{5}{|l|}{ Responsible person } \\
\hline & Husband & Wife & Both, dominantly husband & Both, dominantly wife & Others \\
\hline Herding & $2(1.7)$ & $4(3.4)$ & $35(30)$ & $29(24.7)$ & $47(40.1)$ \\
\hline Supplying fodder & $5(4.3)$ & - & $93(79.4)$ & $18(15.3)$ & $1(0.85)$ \\
\hline Barn cleaning & $2(1.7)$ & $82(70)$ & $5(4.27)$ & $28(23.9)$ & - \\
\hline Milking & $2(1.7)$ & $87(74.3)$ & $11(9.4)$ & $17(14.5)$ & - \\
\hline Milk processing & - & $106(90.5)$ & - & $11(9.5)$ & - \\
\hline Attending sick animals & $91(77.7)$ & - & 21(18) & $5(4.3)$ & - \\
\hline Poultry production & $2(1.7)$ & $55(47)$ & $14(12)$ & $45(38.4)$ & $1(0.85)$ \\
\hline Bee keeping & $75(64)$ & $1(0.85)$ & $37(31.6)$ & $4(3.4)$ & - \\
\hline
\end{tabular}

Source Own Survey, Feb. $2015 *$ Figures in parenthesis are percentages

* Others (children, relatives and herd)

As to the above table, The influence of women is strong in the use of eggs, milk and poultry meat for home consumption and they often have control over marketing and the income from these products. Therefore, women in the Gedeo community take active role in livestock production than in arable farming. Results obtained from FGDs also reveal that the livestock sector almost left for women. This is because men farmers are highly attracted to coffee production. Therefore, from the above data, FGDs and in-depth case interview one can conclude that among the Gedeo community women take the largest share in livestock production.

\subsubsection{Gender Division of Roles in Cash Crop Production}

All respondents have indicated that they produce cash crops. Coffee is the dominant cash crop for domestic and international market while Fruits and vegetables are the second cash crop in the study area produced for local market. Others cash crops include: sweet potato, sugarcane, some grains like sorghum, maize and teff for local market, though insignificant.

\section{(i) Gender Division of Roles in Coffee Production}

Under the traditional settings, women had no role in coffee production. As to the FGDs tasks like planting, weeding, harvesting, storing and marketing coffee were considered as men's responsibilities. The following case explains this point:-

Case-4 the production and marketing of coffee production considered as the economic domain of men.

IN4, 43 years old:- I asked her about whose domain is producing coffee production? She responded that:-

"In our culture, the production and marketing of coffee was regarded as husbands' responsibility.

Our role was to provide meals while they were working at field. Despite sharing certain farm tasks,

stll today the coffee sector considered as the economic domain of men."

In response to the high demand for coffee production in local, national and international markets (economic factors), however, the community began to use women's labor with the view to increase the productivity of the sector as revealed in the FGDs. This finding indeed supports the ideas of Aboma (2000: 67); in his investigation of gender and agricultural production among the Maqi Oromo indicates that women's involvement in agricultural activities largely depends on the wealth and labour needs of the household. Thus, unlike their role under traditional settings, women today are involving in harvesting, storing and marketing activities. Nevertheless, the coffee sector still considered as the economic domain of men (Table 3 ). 
Table 3. Gender division of roles in cash crop production, Coffee.

\begin{tabular}{llll}
\hline \multirow{2}{*}{$\begin{array}{l}\text { Farming Tasks in cash crop } \\
\text { production(coffee) }\end{array}$} & \multicolumn{1}{l}{$\mathbf{( N = 1 1 7 )}$} & \\
\cline { 2 - 4 } & Responsible person & Wife & Both, mainly husband \\
\cline { 2 - 4 } & Husband & - & - \\
Planting & $117(100.0)$ & - & $6(5)$ \\
Weeding & $111(95)$ & - & $111(95)$ \\
Harvesting & $3(2.5)$ & - & $109(93)$ \\
Storing & $8(7)$ & - & $104(88.8)$ \\
Marketing & $13(11.2)$ & - & - \\
\hline
\end{tabular}

Source Own Survey, Feb. $2015 *$ Figures in parenthesis are percentages

As observed from the table, women and men take share of responsibilities in coffee production particularly in harvesting, storing and marketing activities, though with the domination men.

\section{(ii) Gender Division of Roles in Fruits and Vegetables Production}

The production of fruits and vegetables among the Gedeo community held the second position next to coffee as a cash crop. However, unlike coffee, fruits and vegetables are produced only for local market. As to the FGDs, in the past this sector was dominated by husbands'. The income obtained from sale of fruits and vegetables was largely controlled by husband. However, unlike coffee in which women had no role, in the past women share certain tasks in fruits and vegetables production. For instance, women take active role in harvesting, storing and marketing activities. As the economic return from coffee increases men began to leave the sector for their wife. The following point explains this:-
Case -5 the production and marketing of fruits and vegetables are the domain of women.

IN5 is 35 years old. For the question that whose domain is producing and marketing fruits and vegetables? She responded in a way that:-

"In the traditional setting we had better role in fruits and vegetables production unlike coffee and crop production. With the exception of planting and weeding, we share tasks with our husbands in every aspects of the sector. But now due to the expansion of coffee in the area and its good economic returns, men began to leave the cultivation and marketing of fruits and vegetables for us. As a result of this, the bulk of tasks in the sector are taken by us."

The above idea was reflected in women's from plough culture. Thus, in both hoe and plough culture similar patterns of gender division of roles have been observed.

Currently, the responsibility of producing and marketing fruits and vegetables are given dominantly to women among the Gedeo communities. (Table 4).

Table 4. Gender division of roles in cash crop production, Fruits \& Vegetable.

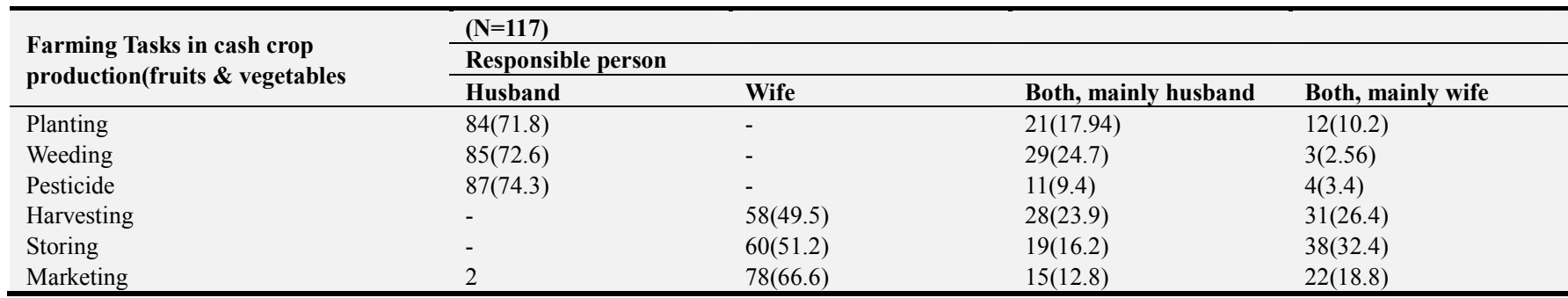

Source Own Survey, Feb. $2015 *$ Figures in parenthesis are percentages

As to the above table, women involve in planting and weeding as well as take significant share of responsibilities in harvesting, storing and marketing activities in the production of fruits and vegetables. What observed in cash crops production is that women help men's tasks in the production of coffee while men help women's task in the production of fruits and vegetables. If a cash crop, and particularly a food cash crop, becomes unprofitable, men tend to lose interest in it, and women may take over its control.

\subsection{Effect of Patterns of Cash Cropping on Gender Division of Roles}

With regard to the question, does cash cropping and land use allocation for cash crops changed the gender division of roles in agricultural production? The majority of farmers responded in affirmative way. A significant 104 (88.8\%)) number of respondents indicated that cash cropping and land use for cash crop changed the gender division of role in agricultural production while (13)11.2\% responded that gender division of roles is not changed due to cash cropping and land use for cash crops. In the traditional Gedeo community, almost all tasks in coffee production were carried out by men. In the community women were culturally considered as playing supplementary role in providing husbands' with meals. However, the production and expansion cash crops both coffee and fruits and vegetables caused men and women farmers' to take active role in the sector. The use of men labor alone found insufficient to boost coffee production. Thus, men farmers' sought women's labor in the sector. As result, share of responsibilities have been 
observed in coffee production particularly in harvesting, storing and marketing activities (Table 3). At the same time, women take the largest share in the production and marketing of fruits and vegetables unlike their role under the traditional settings (Table 4).

Table 5. Elements of change in gender division of roles due to patterns of cash cropping.

\begin{tabular}{|c|c|c|c|c|c|}
\hline \multirow{2}{*}{ Changes in gender division of roles } & & \multicolumn{4}{|l|}{$(\mathrm{N}=101)$} \\
\hline & & Freque. & $\%$ & Valid \% & Cumulative \% \\
\hline \multirow{3}{*}{ Woman's role in the production of food crops } & Increased & 27 & 46.2 & 26.7 & 26.7 \\
\hline & Decreased & 44 & 75.2 & 43.5 & 43.5 \\
\hline & Remained the same & 30 & 51.2 & 29.7 & 100.0 \\
\hline \multirow{3}{*}{ Woman's role in the production of cash crops } & Increased & 61 & 87.2 & 60.3 & 60.3 \\
\hline & Decreased & 15 & 25.3 & 14.85 & 76.9 \\
\hline & Remained the same & 25 & 44.7 & 24.7 & 100.0 \\
\hline \multirow[t]{2}{*}{ Woman's role in the over all agricultural production } & Decreased & 11 & 18.9 & 11 & 82.7 \\
\hline & Remained the same & 27 & 46.3 & 26.7 & 100.0 \\
\hline \multirow{3}{*}{ Man's role in food crops production } & Increased & 22 & 35.8 & 21.7 & 21.7 \\
\hline & Decreased & 57 & 97.5 & 56.4 & 75.0 \\
\hline & Remained the same & 23 & 39.2 & 22.7 & 100.0 \\
\hline \multirow[b]{2}{*}{ Man's role in cash crops production } & Increased & 67 & 88.6 & 63.3 & 63.3 \\
\hline & Decreased & 9 & 15.4 & 8.9 & 71.2 \\
\hline \multirow[t]{2}{*}{ Man's role in the overall agricultural production } & Decreased & - & - & - & - \\
\hline & Remained the same & 35 & 60.3 & 34.65 & 100.0 \\
\hline \multirow{3}{*}{ Use of land in-favor of cash crops like coffee } & Increased & 74 & 94.1 & 73.2 & 73.2 \\
\hline & Decreased & - & - & - & - \\
\hline & Remained the same & 27 & 44.0 & 26.7 & 100.0 \\
\hline \multirow{3}{*}{ Allocation of land for food crops } & Increased & - & - & - & - \\
\hline & Decreased & 76 & 96.5 & 75.2 & 75.2 \\
\hline & Remained the same & 25 & 42.6 & 24.7 & 100.0 \\
\hline \multirow{3}{*}{ Woman's access to land } & Increased & 77 & 97.8 & 76.2 & 76.2 \\
\hline & Decreased & - & - & - & - \\
\hline & Remained the same & 24 & 40.3 & 23.7 & 100.0 \\
\hline
\end{tabular}

Source Own Survey, March 2015

As to the above table, both men's and women's role in the production of food crops has decreased. However, women's and men's role in the production of cash crops has increased. As revealed in the FGDs, stakeholders' supports in providing agricultural inputs and extension services have been increased in the last twenty years. This support increased the productivity of the cash economy sector and helped farmers of the study area to obtained cash from the sector. This inturn encouraged women and men farmers in the study area to participate highly in the production of cash crops.

In the study area use of land for cash crops has increased. However, land allotted for food crops has diminished. As to the FGDs, in-depth case interview and key informant interview, the expansion of cash crops, both coffee and fruits and vegetables in the study area forced men and women to leave the food sector in favor of cash crops. Thus, the increased role of men (in the cultivation and marketing of coffee) and women (in cultivation and marketing of fruits and vegetables) in the cash economy sector created a negative influence on the food sector. Due to a higher rate of return from coffee production farmers of the study area began to clear enset and some other food crops cultivation in favor of coffee production. This clearance of enset production, which is the staple food among the Gedeo community, coupled with high rate of population growth created problem on food productivity in the study area. The argument presented by
Koehler (1999) also tends to support the condition in the Gedeo community. Asymmetric supports in favor of largescale commercialized coffee production have put household food production and subsistence farming, and the livelihoods of those involved, at risk (Koehler, 1999). This revealed in the in-depth case interview in the way that:-

Case- 6 the expansion of cash crops production affected food productivity in the study area negatively.

IN6, is 48 years old. I asked her about how cash crop expansion affected food production? She responded in a way that:-

"For instance enset production among the Gedeo community used to be largely produced for local market and for the central market. However, in the last twenty years, enset is cultivated and produced only for household consumption. Even it is not enough for household consumption. This is mainly due to the fact that we are largely engaged in the production of cash crops, coffee and fruits and vegetables."

Thus, the expansion of cash crops in the area attracted farmers to engage more in coffee which negatively affected food productivity in the study area.

The overall roles of women and men in agricultural production have increased. The traditional low involvement of women in agricultural production has now increased due to changes not only in the economic (the integration of the 
community in national and international market through coffee production) but also the socio-cultural (change in resource control and inheritance arrangement), and political (policy reform, land certification) life of the community. Men in the traditional Gedeo community play vital role in agricultural production. However, their involvement was highly limited by the provisions of agricultural inputs, material supports and other supports necessary for agricultural development. Now due to the expansion of extension services, modern agricultural inputs and other technical supports from the concerned bodies targeting cash crops increased men involvement in agricultural production. These all provision helped men and women farmers to take active part in agricultural production (as revealed in-depth case interview, key informant interview and FGDs). Thus, despite the low involvement of men and women in the food sector, the overall roles of men and women in agricultural production have increased.

\section{Conclusion}

The Gedeo community is dominantly agricultural society. Coffee and Fruits \& vegetables production as a cash crop are the major economic activity of the society. The role played by both men and women farmers is fundamental to boost agricultural production and productivity. In this regard, analyzing gender division of roles in the mentioned cash sector would play a great role to address the specific needs and interests of men and women to the end guarantee gender equality and equity. Thus, studying changes and continuity in gender division of roles in the sector helps and analyzing the impact of the expansion of cash cropping on gender division of roles in agricultural production would enable the concerned bodies to devise appropriate policy to impact positively the need of men and women farmers in the study area.

The primary objective of this study is to investigate the expansion of cash cropping and its implication on gender division of roles among the Gedeo farming community.

Accordingly, two research sites, one plough area (TumataChirecha) and the other hoe area (Sugalle) were selected. The finding of this study reveals that there are changes in gender division of roles in hoe and plough culture. In the study area women's roles in agricultural production have increased unlike their role in the traditional settings. However, similar patterns of change have observed in gender division of roles in hoe and plough culture. These changes in gender division of roles in hoe and plough culture are attributable to changes in sociocultural, economic and political life settings of the community. In this regard, the production and expansion of cash cropping as an economic variable; change in resources control and inheritance arrangement as socio-cultural element and policy reform like formal land certification as a political factor contributed a lot for the changes in gender division of roles in agricultural production in the study area. Consequently, in both hoe and plough culture husband and wife take share of responsibilities particularly in weeding, harvesting, storing and marketing activities, although husband still in the community take the biggest share in crop and coffee production. Contrary to this, women take the largest share in fruits and vegetables and livestock production.

The finding of this study discloses that the use of land for cash crop production, particularly for coffee, limited farmers' allocation of land for food crops in the study area. Cash crops in the study area have been expanded at the expense of land covered by enset (false banana) and some roots and grain crops. As a result the food production sector is at stake. If coffee production expanded at the expense of enset and roots crops, the staple food of the local community and thought to be drought resistant crops, food security at the household and community level could face challenges. Therefore, local farmers are advised to promote intensive farming while generating better income and investing the same on food production and productivity to secure food security. The concerned bodies shall also provide the necessary support for both food and cash crops production and productivity in the study area.

\section{Acknowledgment}

The study was accomplished with the assistance of many individuals and institutions. My great appreciation goes to the Woreda Administration in general and Tumata-Chirecha and Sugalle kebele administration in particular for the genuine support and relevant information to undertake the study in their localities. I would like to thank key informant interviewees; members of the focus group discussion and survey respondents all of whom have provided useful information for the study. I am also thankful for $\mathrm{Mr}$. Sintayehu Belay for reviewing the manuscript and providing valuable input and insight to improve it. I extend special thanks to my colleagues Dr. Addisu Getachew and Mr. Bamlaku Simegnew, staff members at Dire Dawa University, for their assistance in editing the final article.

\section{References}

[1] Abera G, Gudeta H, Belissa M, Shale G, Degefe A, Akassa B (2006). Gender Based Roles and Resource Use Right in Potato Production and Marketing System: The Case of Some Districts in Oromia, Ethiopia. A Research Report. Addis Ababa: OARI and OSSREA.

[2] Aboma, R. (2000) Gender and Agricultural Production among Maqi Oromo, MA thesis, Addis Ababa, Ethiopia: Department of Sociology and Social Anthropology, Addis Ababa University.

[3] Agricultural Learning and Impacts Network (ALINe), (2011). P4P and Gender: Literature Review and Fieldwork Report Version 1.

[4] Boserup, E. (1970), “Women's Role in Economic development. New York: St. Martin Press, Inc.

[5] Bogalech Alemayehu (2001), "Indigenous Conservation Practices in North Shewa Administrative Zone, Amhara Regional State". In "Environment and Development in Ethiopia' Zenebework Tadesse (2001). Forum for Social Studies, Addis Ababa. 
[6] Carr, E. R. (2008) 'Men's Crops and Women's Crops: The importance of gender to the understanding of agricultural and development outcomes in Ghana's Central Region', World Development, 36(5):900-915.

[7] Central Statistical Authority (CSA, 2008), Summery and Statistical Report of the 2007 Population and Housing Census. Federal Democratic Republic of Ethiopia Population Census Commission. AA.

[8] CSA (Central Statistical Agency) and ICF International. 2012. Ethiopia Demographic and Health Survey 2011. Addis Ababa, Ethiopia and Calverton, Maryland, USA: Central Statistical Agency and ICF International.

[9] Croppenstedt, A., Goldstein,M. and Rosas, N. (2013) 'Gender and Agriculture: Inefficiencies, segregation, and low productivity traps', The World Bank Research Observer, 28(1):79-109.

[10] Dejene A (2003). Integrated Natural Resources Management to Enhance Food Security: The Case for Community-Based Approaches in Ethiopia. Working Paper No.16. Rome: Food and Agriculture Organization of the United Nations.

[11] Diksha Arora (2014). Gender division of labor and farm production in subsistence households* Department of Economics, OSH 343, 260 S. Central Campus Drive, University of Utah, Salt Lake City, UT 84112, email: diksha.arora@economics.utah.edu

[12] Doss, Cheryl R. Twenty-five years of research on women farmers in Africa: Lessons and implications for agricultural institutions; with an annotated bibliography. (1999). CIMMYT Economics Program paper No. 99-02. Mexico D. F.

[13] Doss, C. R. and Morris, M. L. (2001) 'How Does Gender Affect the Adoption of Agricultural Innovations? The case of improved maize technology in Ghana', Agricultural Economics, 25: 27-39.

[14] Doss, C. (2002). Men's crops? Women's crops? The gender patterns of cropping in Ghana. World Development, Vol. 30, No. 11 , pp. 1987-2000.

[15] ECSC (2008), Research Methods and Techniques, Course Handbook II. Addis Ababa, Ethiopia.

[16] Ethiopia Ministry of Foreign Affairs, (2010). Techinoagriculture innovation for poverty alleviation. Addis ababa.

[17] FAO, (1995), FAO Conference Twenty- Eight Session 20 Oct.-2 Nov., 1995). "FAO Plan of Action for Women in Development."

[18] FAO, (2007b). "Women and Food Security." FAO, Rome. FAO. 1998. Village Chicken Production Systems in Rural Africa. Household Food Security and Gender Issues, by A. J. Kitalyi. The Food and Agriculture Organization, Rome.

[19] FAO (Food and Agricultural Organization of the United Nations), (2008). Women and sustainable food security towards sustainable food security publication. Women and Population Division, FAO, Rome, Italy.

[20] FAO, (2011) The State of Food and Agriculture 2010-11: Women in agriculture, closing the gender gap for development, Rome, Italy: Food and Agriculture Organization /www.fao.org/docrep/013/i2050e/i2050e.pdf

[21] FAO. (2011b). The State of Food and Agriculture: Women in
Agriculture: Closing the Gender Gap for Development. Rome, Italy: Food and Agriculture Organization of the United Nations.

[22] FAO. (2012). "Cooperatives: Empowering women farmers, improving food security." Accessed January 15, 2013.

[23] www.fao.org/gender/gender-home/gender-insight/genderinsightdet/en/c/164572/

[24] Fernando P 1998. Gender and Rural Transport. Gender, Technology and Development, 2: 63-80.

[25] Gawaya, R. (2008) 'Investing in women farmers to eliminate food insecurity in southern Africa: Policyrelated research from Mozambique', Gender \& Development, 16(1): 147-159.

[26] Gebru, M. G. (2011) Breaking the Norms: Gender and Land Rights in Tigray Ethiopia, MA thesis, Ås, Norway: Department of International Environment and Development Studies (Noragric), Norwegian Universityof Life Sciences.

[27] Gobezie, G. (2010). "Empowerment of Women in Rural Ethiopia: A review of Two Microfinance Models." Praxis: The Fletcher Journal of Human Security XXV: 23-38.

[28] Guèye, E. F. (2000). The Role of Family Poultry in Poverty Alleviation, Food Security and the Promotion of Gender Equality in Rural Africa. Outlook on Agriculture, Vol. 29(2): 129-136.

[29] Guyer, J. (1984), "Women in the Rural Economy: Contemporary Variations," in Hay and Sticher (eds.) African Women: South of The Sahara. Pp. 19-32. London: Longman.

[30] Henn, J. K. (1984), "Women in the Rural Economy: Past, Present and Future," in Hay and Sticher (eds.) African Women: South of the Sahara. Pp. 1-18. London: Longman.

[31] Hjorts, M. I., 2005. Watershed development programme, development support to the Indian agriculture sector, ministry of foreign affairs of Denmark, October 28, 2005.

[32] Holden, S. T., Deininger, K. and Ghebru, H. (2011) 'Tenure Insecurity, Gender, Low-cost Land Certification and Land Rental Market Participation in Ethiopia', The Journal of Development Studies, 47(1): 31-47.

[33] Ibnouf, F. O. (2009) 'The Role of Women in Providing and Improving Household Food Security in Sudan: Implications for Reducing Hunger and Malnutrition', Journal of International Women's Studies, 10(4): 144-167.

[34] Japan International Cooperation Agency (JICA), (1999). Country WID Profile (Ethiopia). Tokyo: JICA Planning Department. With the exception of female heads of households, women have minimal role in decisions related to land distribution and agricultural production.

[35] Jones, N., Y. Tafere, and T. Woldehanna. (2010). Gendered risks, poverty and vulnerability in Ethiopia: To what extent is the Productive Safety Net Programme (PSNP) making a difference? London: Overseas Development Institute.

[36] Kebede, M. (2009) 'The Gender Perspective of Household Food Security in Meskan District of the Gurage Zone, Southern Ethiopia', African Research Review, 3(4):31-47 Scanlan, S. J. (2004) 'Women, Food Security, and Development in Less-Industrialized Societies: Contributions and challenges for the new century', World Development, 32(11):1807-1829. 
[37] Kevane, M. and Gray, L. C. (1999) 'A Woman's Field is Made at Night: Gendered Land Rights and Norms in Burkina Faso', Feminist Economics, 5(3): 1-26.

[38] Mollel NM, Mtenga NA (2000). Gender Roles in the Household and Farming Systems of Techenzema, MorogoroTanzania. South African Journal of Agricultural Extension, 29: 73-88.

[39] Okali, C. and J. Mims. (1998). 'Gender and Smallholder Diary Production in Tanzania.' Report to the Livestock Production Programme of the Department for International Development (DFID): Appendix 1 and 2 pp. 37-38

[40] Sida (2003). A Profile on Gender Relations. Towards Gender Equality in Ethiopia; Division for Policy and Socio-Economic Analysis Author: Haregewoin Cherinet and Emebet Mulugeta Print: Edita Sverige AB, 2003 Art. no: SIDA2138en.

[41] Sintayehu, Dejene (2000), "Gender Roles in agricultural Production among the Sidama of South Western Ethiopia". MA thesis in Social Anthropology, School of Graduate Studies, A. A. U.

[42] Tangka F. K., Jabbar M. A. and Shapiro B.I. (2000). Gender roles and child nutrition in livestock production systems in developing countries: A critical review. Socio-economics and Policy Research Working Paper 27. ILRI (International Livestock Research Institute), Nairobi, Kenya.

[43] Teshome A, Devereux S (2005). Inequality and Agriculture in Ethiopia: A Case Study. WDR 2006 Background Paper on Asset Inequality and Agricultural Productivity. University of Sussex, UK: Institute of Development Studies, Department for International Development (DfID).

[44] Tiruneh, A., Tesfaye, T., Mwangi, W. and Verkuijl, H. (2001)
Gender Differentials in Agricultural Production and DecisionMaking Among Smallholders in Ada, Lume and Gimbichu Woredas of the Central Highlands of Ethiopia, Mexico DF, Mexico: International Maize and Wheat Improvement Center (CIMMYT) and Ethiopian Research Organization (EARO).

[45] Todaro, P. M. (1989), "Economic Development in the Third World, Fourth Edition," 'The Important Role of Women'. Longman Inc, 95 Church Street, White Plains, N.Y. 10601.

[46] Tung, D. X. (2005). "Smallholder Poultry Production in Vietnam: Marketing Characteristics and Strategies." Paper presented at the workshop Does Poultry Reduce Poverty? A Need for Rethinking the Approaches, 30-31 August. Copenhagen, Network for Smallholder Poultry Development.

[47] USAID (United States Agency for International Development). (2012). "Promoting Women in Cooperatives in Ethiopia: for Agricultural Value Chains Development.” Report of Consultation held in Addis Ababa, January 25-26, 2012.

[48] Wessen Shiferaw (2008), "Gender Based Division of Labor in Agricultural Production among the Mejangir Community in South Western Ethiopia.” School of Graduate Studies, AAU.

[49] Wonago woreda agricultural and Rural Development Office, (2015). Women and their contribution to the livestock sector.

[50] World Bank. 2007. World Development Report 2008: Agriculture for Development. Washington, DC: World Bank.

[51] World Bank. 2009. Gender in Agriculture. Sourcebook. Washington, DC: World Bank.

[52] Yngstrom, I. (2002) 'Women, Wives and Land Rights in Africa: Situating gender beyond the household in the debate over land policy and changing tenure systems', Oxford Development Studies, 30(1):21-40. 